\title{
Frequency of rare recessive mutations in unexplained late onset cerebellar ataxia
}

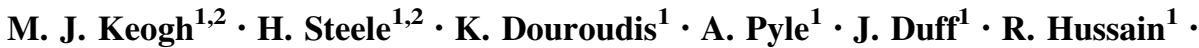 \\ T. Smertenko ${ }^{1}$ H. Griffin ${ }^{1}$ - M. Santibanez-Koref ${ }^{1} \cdot$ R. Horvath ${ }^{1,2}$. \\ P. F. Chinnery ${ }^{1,2}$
}

Received: 24 February 2015/Accepted: 29 April 2015/Published online: 16 May 2015

(c) The Author(s) 2015. This article is published with open access at Springerlink.com

\begin{abstract}
Sporadic late onset cerebellar ataxia is a welldescribed clinical presentation with a broad differential diagnosis that adult neurologists should be familiar with. However, despite extensive clinical investigations, an acquired cause is identified in only a minority of cases. Thereafter, an underlying genetic basis is often considered, even in those without a family history. Here we apply whole exome sequencing to a cohort of 12 patients with late onset cerebellar ataxia. We show that $33 \%$ of 'idiopathic' cases harbor compound heterozygous mutations in known ataxia genes, including genes not included on multi-gene panels, or primarily associated with an ataxic presentation.
\end{abstract}

Keywords Ataxia - Whole exome sequencing $\cdot$ Next generation sequencing $\cdot$ Diagnosis

\section{Introduction}

Adult onset cerebellar ataxia poses a considerable diagnostic challenge. Initial investigations focus on detecting degenerative, toxic, structural and inflammatory etiologies

M. J. Keogh and H. Steele contributed equally to this work and R. Horvath and P. F. Chinnery contributed equally to this work.

Electronic supplementary material The online version of this article (doi:10.1007/s00415-015-7772-x) contains supplementary material, which is available to authorized users.

\section{P. F. Chinnery}

p.f.chinnery@ncl.ac.uk; patrick.chinnery@ncl.ac.uk

1 Institute of Genetic Medicine, Newcastle University, Newcastle upon Tyne NE1 3BZ, UK

2 Department of Neurology, Royal Victoria Infirmary, Newcastle upon Tyne NE1 4LP, UK which together underlie around a third of cases [1]. Thereafter, molecular investigations for a monogenic basis of disease are often undertaken despite $80 \%$ of patients having no relevant family history [2].

Current molecular investigations for sporadic cases echo that of familial forms, beginning with testing for trinucleotide repeat disorders, such as the spinocerebellar ataxias (SCA1, 2, 3, 6, 7 and 17), dentatorubral pallidoluysian atrophy (DRPLA) and Friedreich's ataxia (FDR) in most centres [1]. However, this approach fails to identify a molecular diagnosis in $87-98 \%$ of late onset sporadic cases [1, 3], and subsequent investigations are undertaken on a gene-by-gene basis, often at considerable time and expense.

The difficulty in establishing monogenic forms of disease using this approach is increasingly challenging given that at least 60 causative ataxia genes are reported [4]. Recent studies have therefore utilized next generation sequencing focusing on infantile or juvenile onset cases [5], or adult onset ataxia with a demonstrable family history [4]. Only two studies have described sub-sets of patients with sporadic onset adult disease, despite it being a major form of ataxia, and suggested that a molecular diagnosis can be reached in $\sim 10 \%$ of cases [4, 6]. Given this, we applied whole exome sequencing to a cohort of individuals with sporadic late onset ataxia.

\section{Methods}

Unrelated individuals with sporadic ataxia beginning at 30 years of age or over were identified from routine referrals to our regional neurogenetic service, in Newcastle upon Tyne, England. 
Acquired causes of ataxia were excluded and all participants had negative genetic testing for SCA 1, 2, 3, 6, 7, 17, DRPLA and Friedreich's Ataxia (FA). In addition, all adult males had negative FMRI testing.

Blood genomic DNA was fragmented, exome enriched and sequenced (Nextera Rapid Exome Capture $37 \mathrm{Mb}$ and HiSeq 2000, 100 bp paired-end reads). In-house bioinformatic analysis included alignment to UCSC hg19, using BWA as aligner and GATK to detect SNV and INDELS across all samples using standard filtering parameters according to GATK Best Practise Recommendations [7] (see supplementary methods). Further analysis was performed on variants with a minor allele frequency $<0.005$ in several reference databases and 302 unrelated in-house controls (see supplementary methods). Rare heterozygous, homozygous and compound heterozygous variants were defined, and protein altering and/or putative 'disease causing' mutations as predicted by at least three out of four software programmes were included. Pathogenicity was defined in accordance with American College of Medical Genetic guidelines (see supplementary methods). Genes known or suggested to cause ataxia as a primary or secondary phenotype in humans from two suggested clinical panels $[4,8]$ together with additional genes in which ataxia may result as part of the phenotype (list-supplementary methods) were assessed for variants according to the above criteria, and confirmed by Sanger sequencing (supplementary methods).

Variants were defined using a priori criteria: (1) confirmed pathogenic: dominant disorders-variant previously shown to cause ataxia in humans; recessive disorderseither 2 variants previously shown to cause ataxia in humans; or 1 pathogenic variant with a second variant predicted to affect protein function by at least 3 of 4 prediction algorithms (SIFT, Polyphen2, Mutation Taster, LRT), or through frameshift or truncation. (2) Probable pathogenic: dominant and recessive disorders-variants in known genes causing ataxia in humans and predicted to affect protein function by at least three of four prediction algorithms; (3) uncertain significance: dominant and recessive disorders-variants predicted to affect protein function with weak evidence that gene alteration causes ataxia in humans.

The study was granted ethical approval from a Research Ethics Committee based in the North of England.

\section{Results}

\section{Population}

Twelve Caucasian individuals of British origin (5 male) with no known consanguinity were included (Table 1). Mean age at disease onset was 46.7 years (SD 11; range
30-70 years). Mean disease duration was 16.6 years (SD 6.9; range 6-30 years). For one patient, the disease duration fell within the range expected for multi-system atrophy [9]. This patient had a normal DaTscan and autonomic function tests. Three individuals had CSF examination with negative oligoclonal bands. Five had nerve conduction studies; two of which were abnormal. Detailed clinical features and the results of clinical investigations are shown in Table 1.

\section{Diagnosis}

We identified previously described pathogenic mutations in four of the $12(33 \%)$ patients in our cohort. All were present on confirmatory Sanger sequencing. No probable pathogenic variants were identified and variants of uncertain significance were found in an additional two cases (17\%). Findings are summarised in Table 2.

\section{Discussion}

We identified confirmed or probable pathogenic variants causing sporadic late onset ataxia in four patients $(33 \%)$ in our cohort. These findings are comparable to childhood/ adolescent ataxia using targeted sequencing panels (40\%) [4] and whole exome sequencing (27\%) [5]. They are also significantly higher than previous data for adult onset cases using either panels or whole exome (both 10\%) [4, 6].

We detected pathogenic variants in SPG7, SYNE1 and ANO1O (previously published by Balreira et al. [10]). Fogel et al. [6] also identified pathogenic variants in these genes $(\operatorname{SPG7}(n=2)$, SYNE1 $(n=3)$ and ANO1O $(n=1)$. The clinical features of these patients appear relatively homogenous between their and our study, with pure cerebellar ataxia beginning above the age of 40 for $A N O 10$ and SYNE1 cases, and a more heterogeneous age of onset $(<20-50)$ with additional neurological features including spasticity and a polyneuropathy in SPG7 cases [6]. Therefore, pathogenic mutations in these genes appear to be an important and frequently identified cause of late onset sporadic ataxia.

We used whole exome sequencing (WES) rather than targeted next generation 'panels', and it remains a contentious issue as to which is more appropriate in the investigation of neurogenetic disorders. WES enables greater genome coverage, and hence detection of pathogenic mutations in genes not considered as having ataxia as a primary phenotype. Our results highlight this as $S P G 7$ was not covered by one ataxia panel [4], SYNE1 by another [8], and ANO10 was not included in either panel. WES however, may result in detection of unexpected findings such as pathogenic mutations predisposing to cancer or neurodegenerative 


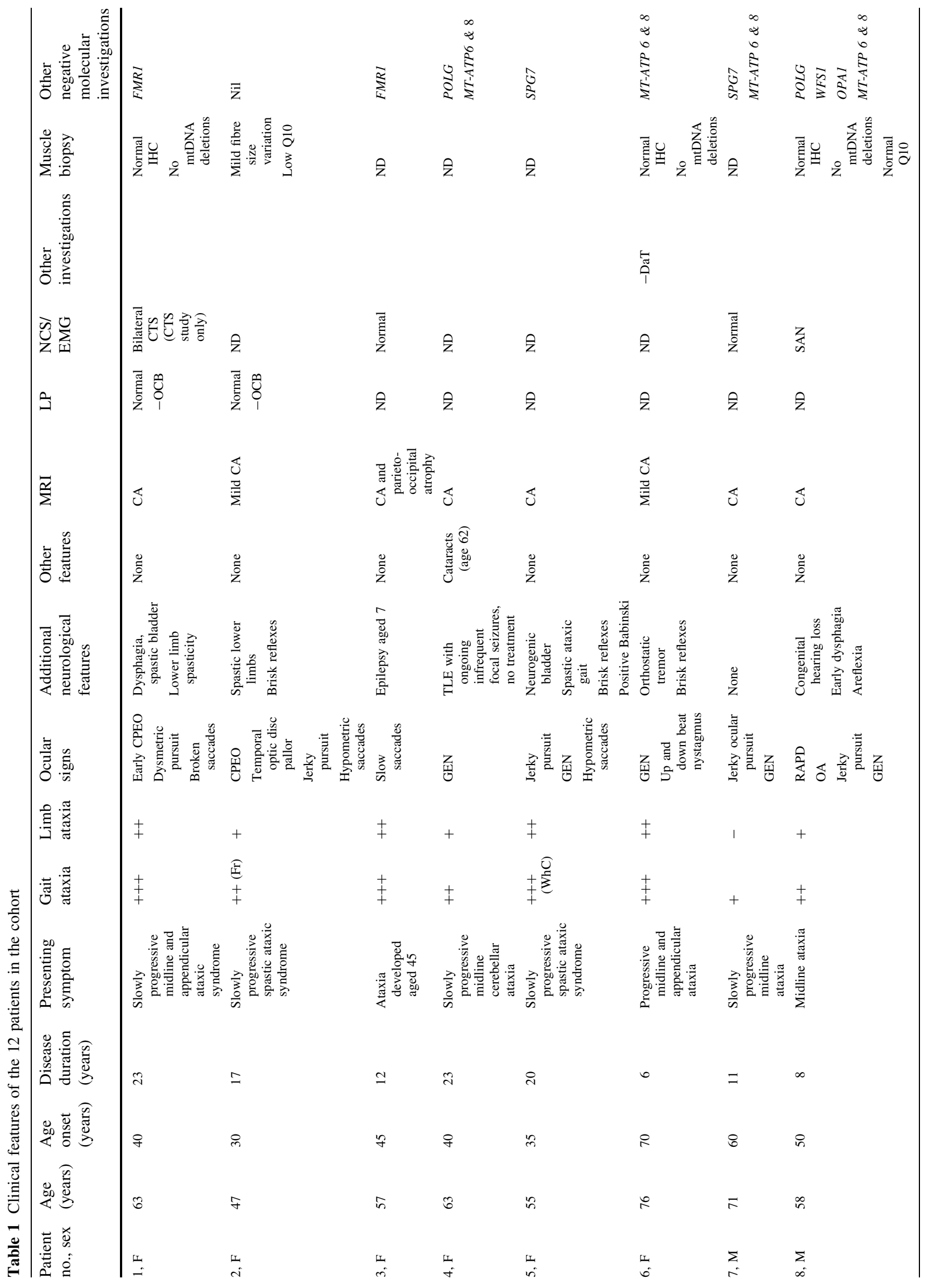




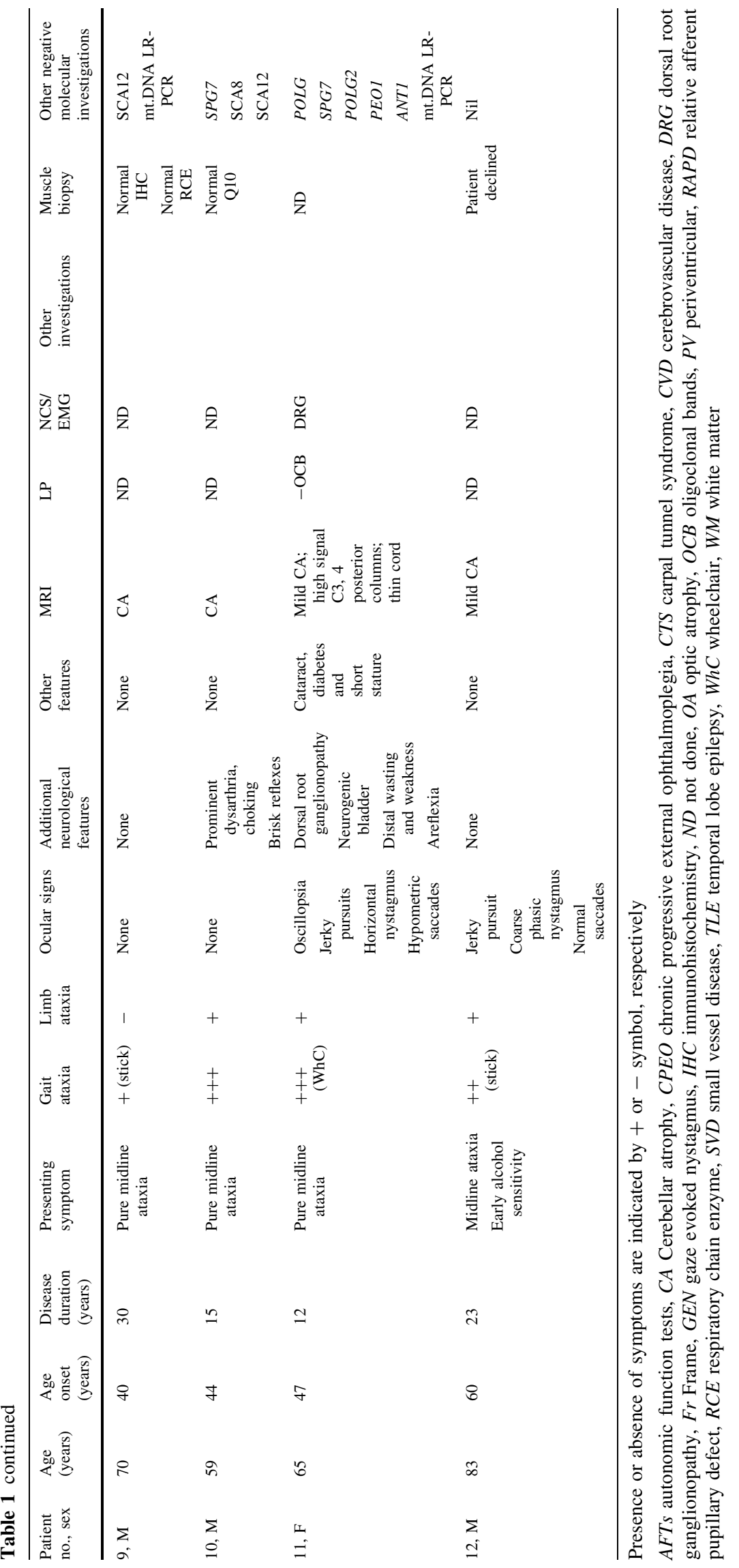


Table 2 Genetic variants of interest identified in the 12 patients

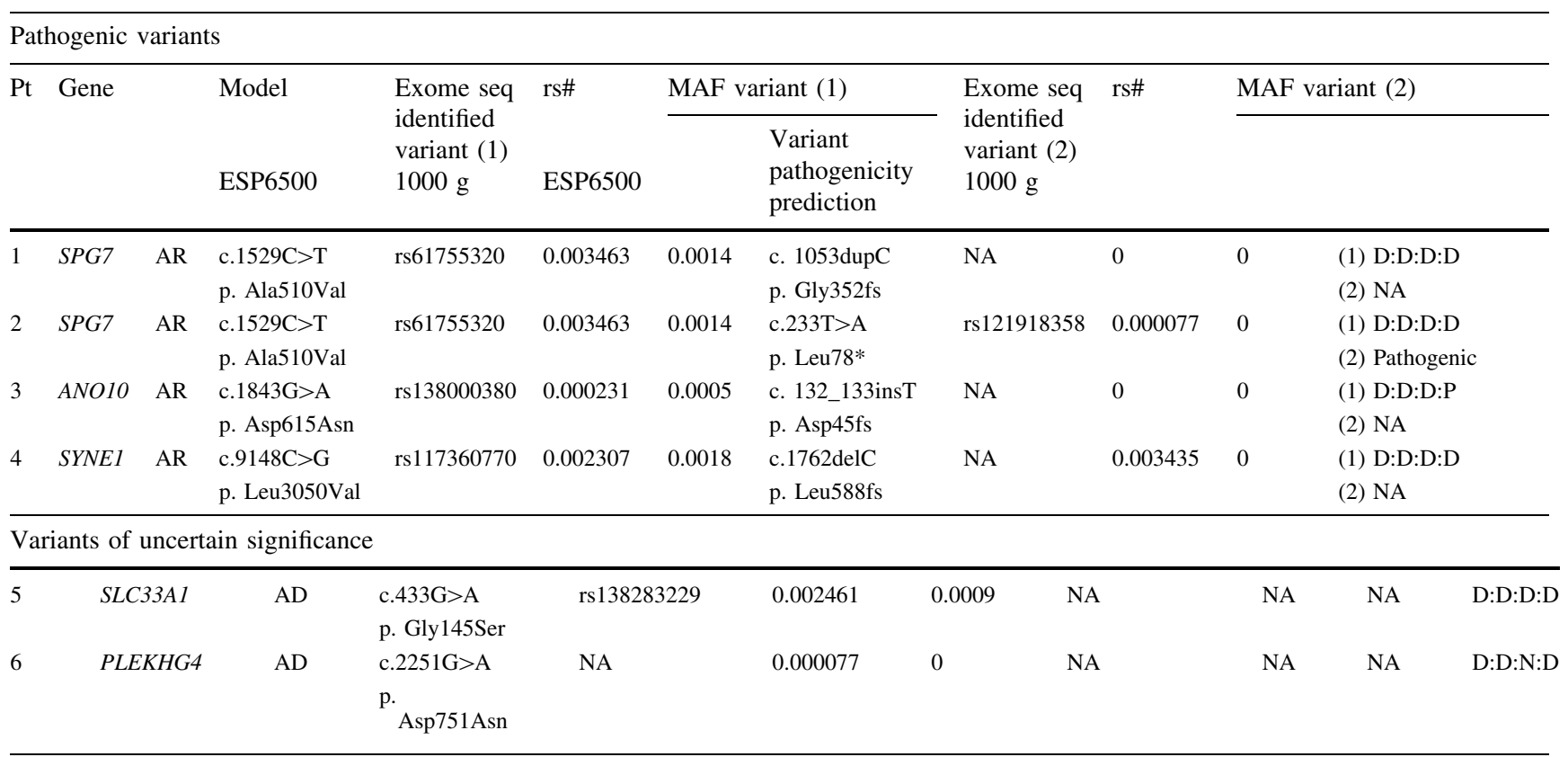

Confirmed pathogenic: dominant disorders-variant previously shown to cause ataxia in humans; recessive disorders-either 2 variants previously shown to cause ataxia in humans; or 1 pathogenic variant with a second variant predicted to affect protein function by at least 3 of 4 prediction algorithms (SIFT, Polyphen2, Mutation Taster, LRT), through frameshift or truncation. Variants of uncertain significance: dominant and recessive disorders - variants predicted to affect protein function with weak evidence that gene alteration causes ataxia in humans

$D$ pathogenic or deleterious, $P$ polymorphism, $N A$ not applicable $N$ neutral (frameshift mutations considered pathogenic)

disease, which must be considered and included in appropriate consent procedures. It must also be noted that neither WES nor targeted panels are appropriate to screen for genomic rearrangements or trinucleotide repeat sequences.

Determining pathogenicity can be challenging for heterozygous variants without a family history of disease and additional living family relatives for segregation analysis. In our cohort, we found heterozygous variants in SLC33A1 and PLEKHG4 in single cases (Table 2). Heterozygous mutations in SLC33Al have been associated with spastic paraplegia (SPG42) with ataxia in a single family, and likewise, missense mutations in PLEKHG4 have been implicated in dominant late onset forms of spinocerebellar ataxia in Japanese individuals. Despite the rarity and putative pathogenicity of the variants in our patients, the lack of data to test segregation makes attributing pathogenicity difficult. As NGS begins to develop larger variant datasets in rare diseases it is vital to share such data through collaborative projects which may aid pathogenicity confirmation through the identification of the same or related variants in unrelated families with a similar phenotype.

In conclusion, we have demonstrated that application of WES to a cohort of unrelated individuals following exclusion of common trinucleotide repeat disorders establishes a molecular cause of disease in a third of cases. These findings have significant implications for clinical practise.
Acknowledgments MJK is a Wellcome Trust Clinical Research Training Fellow. PFC is an Honorary Consultant Neurologist at Newcastle upon Tyne Foundation Hospitals NHS Trust, is a Wellcome Trust Senior Fellow in Clinical Science (101876/Z/13/Z), and a UK NIHR Senior Investigator. PFC receives additional support from the Wellcome Trust Centre for Mitochondrial Research (096919Z/11/ Z), the Medical Research Council (UK) Centre for Translational Muscle Disease research (G0601943), and EU FP7 TIRCON, and the National Institute for Health Research (NIHR) Newcastle Biomedical Research Centre based at Newcastle upon Tyne Hospitals NHS Foundation Trust and Newcastle University. The views expressed are those of the author(s) and not necessarily those of the NHS, the NIHR or the Department of Health. RH was supported by the Medical Research Council (UK) (G1000848) and the European Research Council (309548)

Conflicts of interest The authors report no conflicts of interest.

Open Access This article is distributed under the terms of the Creative Commons Attribution 4.0 International License (http:// creativecommons.org/licenses/by/4.0/), which permits unrestricted use, distribution, and reproduction in any medium, provided you give appropriate credit to the original author(s) and the source, provide a link to the Creative Commons license, and indicate if changes were made.

\section{References}

1. Abele M, Burk K, Schols L, Schwartz S, Besenthal I, Dichgans J, Zuhlke C, Riess O, Klockgether T (2002) The aetiology of sporadic adult-onset ataxia. Brain J Neurol 125:961-968 
2. Muzaimi MB, Thomas J, Palmer-Smith S, Rosser L, Harper PS, Wiles CM, Ravine D, Robertson NP (2004) Population based study of late onset cerebellar ataxia in south east Wales. J Neurol Neurosurg Psychiatry 75:1129-1134

3. Pujana MA, Corral J, Gratacos M, Combarros O, Berciano J, Genis D, Banchs I, Estivill X, Volpini V (1999) Spinocerebellar ataxias in Spanish patients: genetic analysis of familial and sporadic cases. The Ataxia Study Group. Hum Genet 104:516-522

4. Nemeth AH, Kwasniewska AC, Lise S, Parolin Schnekenberg R, Becker EB, Bera KD, Shanks ME, Gregory L, Buck D, Zameel Cader M, Talbot K, de Silva R, Fletcher N, Hastings R, Jayawant S, Morrison PJ, Worth P, Taylor M, Tolmie J, O'Regan M, UK Ataxia Consortium, Valentine R, Packham E, Evans J, Seller A, Ragoussis J (2013) Next generation sequencing for molecular diagnosis of neurological disorders using ataxias as a model. Brain J Neurol 136:3106-3118

5. Sawyer SL, Schwartzentruber J, Beaulieu CL, Dyment D, Smith A, Warman Chardon J, Yoon G, Rouleau GA, Suchowersky O, Siu V, Murphy L, Hegele RA, Marshall CR, FORGE Canada Consortium, Bulman DE, Majewski J, Tarnopolsky M, Boycott KM (2014) Exome sequencing as a diagnostic tool for pediatriconset ataxia. Hum Mutat 35:45-49

6. Fogel BL, Lee H, Deignan JL, Strom SP, Kantarci S, Wang X, Quintero-Rivera F, Vilain E, Grody WW, Perlman S, Geschwind DH, Nelson SF (2014) Exome sequencing in the clinical diagnosis of sporadic or familial cerebellar ataxia. JAMA Neurol 71:1237-1246
7. Van der Auwera GA, Carneiro MO, Hartl C, Poplin R, del Angel G, Levy-Moonshine A, Jordan T, Shakir K, Roazen D, Thibault J, Banks E, Garimella K, Altshuler D, Gabriel S, DePristo M (2013) From FastQ data to high-confidence variant calls: the Genome Analysis Toolkit best practices pipeline. Curr Protoc Bioinformatics 43:11.10.11-11.10.33

8. Panel NDSN. http://www.sheffieldchildrens.nhs.uk/downloads/ labgenetics/LabGenetics_NGSNDTests.pdf. Accessed 3 Nov 2014

9. Wenning GK, Geser F, Krismer F, Seppi K, Duerr S, Boesch S, Kollensperger M, Goebel G, Pfeiffer KP, Barone P, Pellecchia MT, Quinn NP, Koukouni V, Fowler CJ, Schrag A, Mathias CJ, Giladi N, Gurevich T, Dupont E, Ostergaard K, Nilsson CF, Widner H, Oertel W, Eggert KM, Albanese A, del Sorbo F, Tolosa E, Cardozo A, Deuschl G, Hellriegel H, Klockgether T, Dodel R, Sampaio C, Coelho M, Djaldetti R, Melamed E, Gasser T, Kamm C, Meco G, Colosimo C, Rascol O, Meissner WG, Tison F, Poewe W, European Multiple System Atrophy Study Group (2013) The natural history of multiple system atrophy: a prospective European cohort study. Lancet Neurol 12:264-274

10. Balreira A, Boczonadi V, Barca E, Pyle A, Bansagi B, Appleton M, Graham C, Hargreaves IP, Rasic VM, Lochmuller H, Griffin H, Taylor RW, Naini A, Chinnery PF, Hirano M, Quinzii CM, Horvath R (2014) ANO10 mutations cause ataxia and coenzyme Q(1)(0) deficiency. J Neurol 261:2192-2198 